\title{
Aotearoa New Zealand Kindergarten Parents Reflecting on Kindergarten: 2006-2007
}

\author{
Judith Duncan ${ }^{*}$
}

\author{
University of Canterbury, Private Bag 4800, Christchurch, New Zealand
}

\begin{abstract}
This paper discusses emerging findings from 12 focus group interviews of parents who are currently using kindergarten as the main early childhood education provider for their child/children. These interviews are from a larger national study looking at current kindergarten culture within the early childhood sector of this century. Parents were asked what they liked about kindergarten and what, if any changes they would like to see in the kindergarten provision firstly, for their child and then for the kindergartens as a national service. The wider data from this study is still being compiled and the parents' interviews are at a preliminary analysis stage. The views of the parents are significant for all planning and understanding about the importance of our early childhood sector in the lives of families, and the implications of these early findings will be discussed.
\end{abstract}

Keywords: Early childhood education, parent choice, parent satisfaction, kindergarten.

\section{INTRODUCTION}

In 2006 I began a small qualitative research project, funded by a University of Otago Research Grant, to document and analyse the philosophies and practices of current New Zealand kindergartens. The question shaping this project was whether New Zealanders see the New Zealand Kindergarten service as just another early childhood (EC) education provision, or whether the combination of its history and philosophy continue to make it a distinctive part of New Zealand culture and family experiences. While there have been variations on the theme of 'kindergarten' in New Zealand, the early childhood centres who are called by this name in New Zealand and who are administered by kindergarten associations, have historically held similar philosophies and practices around New Zealand. This traditional philosophy of the New Zealand kindergarten has been maintained in New Zealand for over 100 years. Since the 1980s however, the kindergarten service, once called the 'flagship' within early childhood education [1] has now begun to change in reaction to and in response to the need for 'diversity' and 'responsiveness' to both their communities and the government requirements.

As Graue [2] discusses in her analysis of American kindergartens, any talk of kindergartens can produce a sense of "nostalgia". Many New Zealanders have attended kindergartens as a child themselves, or used them for their children and grandchildren.

Kindergarten, arguably, is as 'New Zealand' as "kiwifruit", "pavlova", and the "buzzy bee"1.

*Address correspondence to this author at the University of Canterbury, Private Bag 4800, Christchurch, New Zealand;

E-mail: judith.duncan@canterbury.ac.nz

\footnotetext{
${ }^{1}$ These are called New Zealand 'icons' and symbolise aspects of New Zealand history and culture.
}

Thus, discussing kindergarten within New Zealand can often come as a surprise: "hasn't it always been there? And won't it always be there?". This 'taken for granted' position however, runs real risks. As Graue [2] sums up, in her analysis of American kindergartens, it is important that we have real conversations about our kindergartens. She argues:

\begin{abstract}
Schools both reflect and shaped the social context in which they work. This two-way street is well illustrated in today's kindergarten, which is evolving to meet the changing needs of today's children and families while also representing trends that early childhood educators have resisted. It might be said that kindergarten is now at a crossroads - and our choice of direction will shape the experiences children will have as they enter elementary school. We need to speak more articulately for kindergarten; making it the focus of a conversation helps clarify its mission. It is too much a part of our memory to lose its past and too crucial an institution to bumble toward the future.
\end{abstract}

This research project has as its core conversations about the New Zealand kindergarten. Conversations, in the form of qualitative interviews with kindergarten association general managers/chief executives, kindergarten senior teachers/professional service managers, kindergarten teachers and kindergarten parents have been held across New Zealand. This paper presents preliminary findings from the focus interviews with kindergarten parents.

\section{NEW ZEALAND KINDERGARTENS}

The New Zealand kindergarten has a long history of early childhood education provision in New Zealand, with the first independent kindergarten opening its doors in 1889 in Dunedin, for the children identified as 'uncared' for and who were often seen as 'unsupervised' on the streets. From these philanthropic beginnings the kindergartens soon spread to other areas of New Zealand as parents and communities 
wished to share in the advantages of early childhood education - kindergarten style.

Kindergarten in New Zealand has followed a free-play philosophy based on the idea of Friedrich Froebel (17821852 ) - the original kindergarten designer. Central to the philosophy of the kindergarten in New Zealand has been to keep the centres as freely available for families as possible i.e. low cost and open to all families irrespective of ethnicity, religion or socio-economic status. To enable this equity of access for all, kindergartens are partly funded by national government funds and to cover the rest needed to operate the kindergartens, the kindergartens are dependent on fundraising and parental contributions (previously known as donations but now called contributions due to new tax and income subsidy rules).

While much has been recorded historically about kindergarten teaching practices and philosophies [3-7] there is very little research on the current decisions and philosophies that are impacting on the kindergarten service, within the wider early childhood education sector. This research has intended to address this gap in New Zealand's current understanding of kindergartens.

Generally, New Zealand kindergartens cater for children who are two to four year-olds (at five years-old children begin compulsory schooling). Historically, all teachers in kindergartens are trained with early childhood qualifications and are also required to be registered. This requirement has now been removed ${ }^{2}$. The children attend kindergarten either in same-age groups in sessional settings, or mixed-age groups in sessional settings, or more recently mixed-aged settings for a school day length $(9.00-3.00,8.30-2.30$ etc). Kindergartens have group sizes of 30 to 45 children and are staffed with one teacher for every 15 children. The daily curriculum is based on Te Whaariki [8] and has a strong focus on parent involvement and participation. All kindergartens are managed by a kindergarten association, who oversee all kindergartens collectively in any given geographical area. In New Zealand there are currently 32 kindergarten associations and 619 kindergartens, where collectively 44,435 children are enrolled [9].

Kindergartens in New Zealand are diverse and constantly changing, despite these shared beginnings. While they may be "universal" they are now far from "uniform" [10] in their hours of operation and structural style of provisions. In a recent study undertaken by Duncan et al. [10] investigating the experiences of under-three year-olds in kindergartens, a nationwide survey demonstrated how diverse and different the everyday contexts of kindergartens across New Zealand had become. The authors, in a later paper, concluded:

The relevance of these findings is that they establish a picture that had not yet existed of the complex micro context in which kindergarten teachers currently work within the broader (macro) context of association policy and strategic planning. In this picture, the world of kindergarten teaching is revealed as no longer ho-

\footnotetext{
${ }^{2}$ The passing of the Education Amendment Act in 2005 removed this requirement and positioned the kindergarten sector with the same requirements of the other early childhood services.
}

mogenous either within Associations or across them. It seems to us that a homogenous approach to kindergarten no longer exists in New Zealand [11].

Kindergartens are changing in both response to and reaction towards changing family and community needs and requirements. As is occurring internationally the increase of working parents, parenting alone families, and family mobility has led many sessional early childhood programmes to relook at their hours of operation and, in the case of kindergartens, to increase their sessions for longer periods [10-13]. In New Zealand falling demographics and increased parental choice over early childhood education has also poised kindergartens in a new 'market', as no longer the leading provider of education for the 3-4 year olds in New Zealand. This has contributed to changes in operational hours and the introduction of younger children to maintain the universal access of kindergartens in local communities [11, 14]. These changes have and can mean very different things for the children and parents who currently attend kindergarten. The research looking at parent choice and satisfaction with their child's/children early childhood centre indicates that there are some key issues to consider, as well as responding to physical changes within the society at any time.

\section{PARENTS AND EARLY CHILDHOOD CHOICES AND EXPERIENCES}

Internationally, research consistently demonstrates parental satisfaction with their choice of childcare, even when independent researchers do not agree with the 'quality' standards of the centre/service in question [15-19]. This has led researchers to investigate the aspects of early childhood education that are deemed to be important to parents in an attempt to understand what sense parents do make of their and their child's experiences in early childhood education and how to support parents to make the best possible choices.

\section{Reasons for Choosing a Particular Early Childhood Service}

In a survey of 345 New Zealand households with children under five years old, combined with 30 in-depth interviews with parents of preschoolers, Robertson, Gunn, Lanumata and Pryor [18] concluded that parents actively "match the service to their child's age, abilities and needs" and thus recommend that there needs to be the continued support for a range of diverse services and for resourcing to enable parents to access the appropriate service for their family (for example, continued provision of low cost services). They emphasise that their research demonstrates how multifaceted the nature of parental decision making for choosing and using early childhood services is [18] and so any simplistic response to perceived reasons for parent's choices needs to be thought about very carefully. However, they concluded in their study that the three most important factors for deciding to use an early childhood service were: quality of services; availability of services; and affordability of services.

Similarly, Mitchell and Brooking [20] found in their survey that the most common set of reasons that parents chose early childhood centres were: quality of teachers and programme; service being locally based; affordability and open- 
ing hours; [availability]; and the philosophy of the service or recommendation from someone else.

Interestingly, location, hours and supporting transition to school were the reasons that differed most for parents who had chosen kindergarten from other parents in the survey [20].

\section{Benefits and Preferences}

Parents' expectations and preferences are also identified as significant factors in choice of early childhood service in current research. Howe et al. identified that parents saw the main benefits of attending an early childhood centre as:

The opportunity for social interaction (74\%), development of independence (22\%), learning routine and discipline (19\%), has a range of experiences $(15 \%)$ and educational foundations (11\%) [18].

Interestingly, given the emphasis on 'educational experiences' as often driving curriculum and provision decisions, research looking at parents' perspectives regularly priorities other benefits before educational. However, emphasis on education appeared to increase with the age of the child in the data from the Robertson et al. [18] study, thus posing the question whether our understanding of our traditional early childhood services as those of 'education' for the older preschool has influenced parents expectations and views of early childhood offerings in the 3 to 4 year-old age group?

Interestingly, they also found that employed parents were more likely to cite benefits to themselves of the early childhood service, over the benefits for the child, while the converse was more likely for parents based at home. For those who chose kindergarten as their preferred early childhood service, Robertson et al. identified that these parents were:

\begin{abstract}
More likely to cite being based near a school as important in choosing a service;

More likely to cited that cost was deciding factor when choosing a service;

Less likely to cite childcare while working as a reason to use ECE;

Less likely to cite the providers philosophy as being a deciding factor in choosing the service

Less likely to cite having suitable opening hours as important in choosing a service

Less likely to cite the possibility of part time or flexible use as important in choosing a service [18].
\end{abstract}

The authors concluded that "kindergarten is also seen as more appropriate for those about to start school and this is reflected in the desire of these parents to have a service located near school". This finding is also supported by Lythe [21] were she discussed proximity to the children's home and the value of the social friendships that were formed for both the child and the parent as a key in the parents choice of their early childhood centre. Wylie, Thompson and Kerslake Hendricks as part of the Competent Child study identified that location was the main reason that parents chose the kindergarten for their child and that they moved their children from other centres when "a more suitable option for the child or parent - usually kindergarten or playcentre - became available" [21].

Thus, those parents who choose kindergarten appear to be able to 'fit' into the existing structures of the kindergarten. However, the New Zealand childcare survey undertaken in 1998 by the Department of Labour and National Advisory Council on the Employment of Women [22] found that there were few differences between which services employed and non-employed mothers chose for their child/children. A key difference however, was that $40 \%$ of the children who were attending a kindergarten, with employed mothers, were also attending another childcare arrangement (either formal or informal) compared with $26 \%$ of children with employed mothers who were not attending kindergarten. This indicates that while kindergarten may be the service of choice, the logistics of managing this can be complex for both the parents and the child. So should kindergartens change their hours and have longer sessions to assist the working parent?

\section{Full Day Kindergarten Versus Half-Day Kindergarten}

While the full-day kindergarten option (of 8 hours) has not yet arrived in New Zealand, the school-day model (9-3, 8.30-2.30 and similar combinations) has gained popularity in many areas of New Zealand, in contrast to the tradition 2-4 hour daily sessions and compared with full-day options in other EC centres. Research looking at the benefits of full-day kindergarten in America and closer to home, Australia, has conflicting results. Greer-Smith, (1990 cited in [13]) points out that while full-day kindergarten may suit parents increased needs for care while they work or study, this may not necessarily be the best option for the child. However, just as the early research on early childhood education focused on whether child care was helpful or harmful [23], several researchers are challenging us that to ask this same style of question towards full or half-day kindergarten, is once again, to ask the wrong question [2].

In a recent survey of 531 early childhood services ${ }^{3}(15 \%$ of all services) in New Zealand, Mitchell and Brooking [20] identified that the majority of parents were satisfied with the times and type of early childhood provision that they were currently using. Interestingly, those who wished to access a different form of early childhood education (14\%) wished especially to be able to access kindergarten [20].

How current parents who are using kindergarten as their early childhood education choice perceive kindergartens currently is the focus of the rest of this paper.

\section{METHOD}

Over late 2006 and the beginning of 2007 I undertook interviews with members of kindergarten associations. After receiving consent from the University of Otago Human Ethics committee, and the New Zealand Kindergarten Incorpo-

\footnotetext{
${ }^{3}$ In the Mitchell and Brooking study, 531 services were survey in a stratified random sample, representing $15 \%$ of all services. Each service as sent one questionnaire for management, two for teachers/educators, and one for each parent committee member or office holder. The full report can be accessed at: www.nzcer.org.nz
} 
rated $^{4}$, I approached twelve associations to undertake case study interviews within their association, and the remaining thirty associations to interview their General Manager/Chief Executive and Senior Teachers/Professional Service Managers. At this point I wish to thank the associations for both their consent and the enthusiasm that they greeted this project with. Not only did many of the associations give me consent to undertake the interviews but also several associations offered interviewer support (teacher and senior teacher interviewers in two associations) and most offered assistance with accommodation and locations for interviewing, recruitment of participants and endless time for me to conduct the many interviews that make up this study.

\section{Case Studies}

Twelve associations were selected for case study interviews consisting of interviews with the General Manager/Chief Executive, Kindergarten Senior Teachers/Professional Service Managers, and focus group interviews with a small group of parents, and another with a small group of teachers. Six associations were in the North Island and six in the South Island, and six were classified as mainly rural and six as mainly urban. They were chosen for a selection of large towns, small towns, rural and urban mix. The focus groups were carried out either at the associations' offices or at a kindergarten in a non-contact session time. Teachers were asked to recruit interested parents, who were not on the committee or on any kindergarten association boards - the aim was to get a range of parents from a range of kindergartens but not ones who were deeply involved in the 'culture of the kindergarten' as can be expected with those who have taken on voluntary management roles in the kindergarten. Similarly, associations were asked to invite teachers who came from different kindergartens and were a mix of head teachers and teachers. While I undertook most of these case studies, three case studies were undertaken in the North Island by research colleagues (one recently retired from Massey University and a current kindergarten teacher and senior teacher).

\section{Phone Interviews}

The rest of the participants in the remaining twenty associations were interviewed by telephone and all the interviews were recorded. The interviews were carried out individually with each General Manager/Chief Executive of the twenty associations but Senior Teachers/Professional Managers were interviewed in their teams where possible, or individually if they were the only members in that role in their association. Three interviews were also held individually due to time constraints on getting teams together for an interview.

\section{Participants}

In total for this project the following from the 32 kindergarten associations were interviewed:

31 General Managers/ Chief Executives; 3 Operational Managers/General Administration Managers; 60 Senior

\footnotetext{
${ }^{4}$ The New Zealand Kindergarten Incorporated (NZKI) is the parent body of 28 kindergartens representing 410 kindergartens. EC Leadership consists of the remaining 4 kindergarten associations representing the remaining 285 kindergartens. (Ministry of Education, 2007).
}

Teachers/Professional Services Managers; 71 teachers from 12 associations (Urban: 34, Rural 37) and 61 parents from 12 associations (Urban: 34 Rural: 27).

\section{Interview Questions}

All participants were asked about the strengths of kindergarten, about the differences or distinctive nature of kindergarten in comparison to other early childhood services, and their views and opinions on the kindergarten's position in contemporary New Zealand culture and for its future. Analysis of the interviews has begun and preliminary summaries prepared.

\section{FINDINGS}

This section looks closely at the responses from the parents in their own words. The responses have been grouped to reflect the summary data but not to repeat the same responses that occurred for different questions.

\section{Kindergarten as the Choice for EC provision}

The 61 parent's responses emphasized both the reasons they chose kindergarten and the things they liked about kindergarten. These have been grouped under the headings of: the socialization opportunities for their child, the focus on their individual child, and the preparation for school. It must also be acknowledged that eight parents stated very clearly that kindergarten provided a break for them, either to do other things or simply as a relief from stress, and that this very role for an early childhood service is an important one for family support, as has been evidenced in other studies [24-30].

The parents also identified that the community-based and community-involvement aspects of the kindergarten (that are also particular to many non-profit centres) was a distinctive aspect of the service that parents enjoyed. Concerns were raised by the parents at society and funding changes which they perceived threatened just those aspects of the kindergarten that had led them to choose kindergarten in the first place, and that they enjoyed the most.

\section{Socialisation for their Child or with Other Children (with a Particular Emphasis on Preferring the 'Same-Age' Child Group}

The parents overwhelmingly cited friendships, and social skills as one of the most important reasons for choosing kindergarten for their child/family. This focus had two parts to it: making friends but also making friends that may persist through to school:

\begin{abstract}
Rural parent: They go to kindy really just to make friends. I like the idea of the making friends and they go to school with those friends. I feel it's got to make it easier when they go to school knowing some faces and - and following the other kids that are a bit older than them too. I think it's got to help.
\end{abstract}

Rural Parent: And I would probably say it's a good place to get them to socialize with adults, as well as with other kids.

In choosing kindergarten serious consideration was given to the advantages of the same-aged grouping of the tradi- 
tional kindergarten structures. This same-age grouping was important to both urban and rural parents and was explicitly contrasted with other EC centres by the parents, where a wider range of ages would be found. Parents commented frequently that they thought that a narrower age grouping of children better served their child's educational needs:

Rural Parent: Well, it's sort of more age group orientated than ... a daycare centre ... where you've got babies right up till they go to school, whereas they're [kindergarten] more centred on a particular age.

Rural Parent: Kindy is totally - is very age very age appropriate. So, you know, they're not - everything that's there is age appropriate for them. Whereas in the other early childhood centre there was, you know, the things - the little things for the babies and what have you.

\section{Child's Individuality and Education being the Focus}

Rural Parent: They bring out the best in your child as an individual and as well as a group, don't they.

Overall, parents appeared to feel that the kindergarten curriculum was very child-centered. They remarked on how the teachers were able to balance the individual versus group work, 'free play' versus more adult directed activities successfully for the children, and were not a 'babysitting service':

$I^{\text {st }}$ Rural Parent: Kindy's like a learning experience. Teaching rather than babysitting. Yeah.

$2^{\text {nd }}$ Rural Parent: I've seen it all, I've been to both, I've seen it.

Several parents contrasted the set activities of other early childhood centres with a 'free play' model and the availability of multiple choices in kindergarten.

Urban Parent: But you know all those opportunities - aside from the socialization - the actual things that are there. The things that they can do, such as the sand and the water and all the different toys, the blocks, all those things that they can play with that - and whatever else there is, you know, that you couldn't really set up in your own home environment.... And if they're playing a game and they need something they can: 'right I need this' - they can go and make it or that - 'cause it's all there. They can go and build it or they can make it out of boxes. Everything's there on tap, which again is ... why I like kindergarten as oppose to the preschool that we used. They had certain things out at certain times whereas kindy, everything's out all the time. I mean they change the puzzles and games and all the rest of it, but you know they always have access to the woodwork, they always have access to the construction and the blocks and the water and the sand. Whereas, often at other places they just have a selection out that they can do, you know, now they are playing a game and they need a car or a boat or whatever, they can get boxes and actually make everything and just do it there and then.

The following parent stressed the value of this way of teaching as encouraging and supporting children to feel as real participants in their learning and development:

Urban Parent: One of the things I really like about kindergarten is the level of imagination that sort of goes on in terms of play. That it's not all kind of - it's not - it's not geared to be play that's convenient for the teachers. You know, like kind of sit down and watch this video or sit down and play this computer game. It's kind of like, it's geared to bring out some sort of creativity amongst the children.... Teachers sort of pick up on those things and they direct - direct their play as well as allowing the kids to create things and be imaginative. And it's ... like your kids are actually doing things rather than just observing or being spectators. Like you get a sense that they're actually real participants. And that they also quite often have to keep themselves occupied. That they're given a little bit of free time in which, you know, they have to actually entertain themselves and work together. Play together and entertain themselves as little groups or bigger groups. So it's a really nice blend of being directed, you know, from mat time, say, sitting down and being told a story but also time in which kids learn to not just sort of hang back and sort of wait to be entertained but actually take responsibility for entertaining themselves, I suppose, and - and playing together yeah. That's - that's another thing I really like about kindergarten [Emphasis added].

\section{Preparation for School}

All of the above factors combined in the perceptions of the parents as creating the context which supported their child's/children's preparation for school. Thirty-nine responses identified as important the fact that at kindergarten their child interacted socially with children of a similar age, and with the same children they would progress on to school with:

Rural Parent: It was the same for me that I wanted my daughter to be going to kindy where she'd be mixing with a lot of the kids that she might be going on to - to school with, but I actually took her out of an early childhood centre that I had her in while I was working part-time to put her into kindy because I just - there was never any question she was going to kindy, it was just something I did when I was a kid and it was - it was a natural progression, you know, school wasn't the first thing, it was kindy, yeah so.

This was important, even if just for a short time before going to school:

Urban Parent: ....and it is like everybody thinks, it's a preparation for school, even if you 
get them there for the last six months before they go to school.

The parents perceived that the large group size and fewer teachers helped this transition towards school, where children were in larger group class numbers with only one teacher.

Urban Parent: At kindy, I think there's less teachers but they're [children] also - they don't - they're not quite as attached to having a teacher there all the time, they get used to having to wait and listen and share, like they will at school.

The parents clearly identified preparation for the demands of schooling as an important function of kindergarten. This preparation for school, while raised by most of the parents, was particularly important for the rural parents. This also supported the child's transition from 'being home with Mum' by providing some independence within a safe, affordable, environment:

Rural Parent: So it's sort of gives [your] child a chance to learn a bit of independence away from you before school and without you having to pay too much.

Nineteen responses discussed kindergarten's role in preparing children for the structure and timetabling of the school day, and a few mentioned that kindergarten taught children to respect the authority of other adults, particularly of teachers. There was a sense that you could tell the children that had come from kindergarten when they started school:

Rural Parent: I can see the difference though in the classroom now 'because my daughter's started school. I can almost tell what kids went to kindy and what kids went to - you know the whole: you learnt that at kindy. They're all putting their hand up, hanging their bag up, and listening, sitting down on the mat, some kids are just climbing the walls and some kids are just totally focused. They lay all the groundwork for that at kindy.

Many of the parents thought that children who attended kindergarten had a better understanding of such things as managing food and eating, places for hanging coats and keeping lunchboxes, and periods of attention and stillness through 'mat time' than did children in other ECE:

Rural Parent: It's - it is a set hours so the kids become familiar, you know, they know, well three afternoons they go to kindy, or every morning they go to kindy. It - it's sort of like a stepping-stone before school. They know that they pack their bag. They know that they take their lunch. They know that they do those things, like school, but it's not the hours and they've still got the freedom before school.

\section{Relationship Building and Community Involvement (for the Parents as Well as the Children)}

The involvement of families in the kindergarten was continually mentioned in regard to most of the questions. Par- ents particularly commented on the amount of parent involvement encouraged at kindergarten and contrasted that with the 'drop and go' anonymity of other ECE:

Rural Parent 1: I suppose for me [name of another centre] was more of a childcare, I don't see kindy as childcare for me.

$2^{\text {nd }}$ Rural Parent: No, no.

$1^{\text {st }}$ Rural Parent: It's not where I go to put my kid so I can hive off and do something, it's her it's her education for school, whereas I put my children into childcare when I needed to go to...

$2^{\text {nd }}$ Rural Parent: More for us.

$1^{\text {st }}$ Rural Parent: ...for, you know, part-time work. It's yeah.

Several of the parents saw huge gains and value in being involved in the kindergarten, not only for the benefit of contributing to keeping the kindergarten funded and supported, but in the enjoyment and pride that their children expressed in having their parent/s involved at 'my kindy':

Urban Parent: Yeah, you can't just drop them off and go away like crèche, you have to actually involve yourself a little, even if you don't want to, you have that little bit of involvement and it makes the children feel better too.

$2^{\text {nd }}$ Urban Parent: It's all about that how community-based it is but also that opportunity to even though it can be a - it's just that need for contribution. You know, like whether it's grounds ... and I think it's kind of good for the kids to see you having that kind of input .... and you know you're welcome ...they love you, there's the fundraising and the...

$1^{\text {st }}$ Urban Parent: ...yeah, well, not that I've been great on that but the - yeah that - that parent help or, you know, if you can...help out and it's just the kids really like you being involved as well, you know.

Connecting with the community was repeatedly remarked on by the parents - both rural and urban parents. The discussions flowed such as in the following example:

Urban Parent 1: But its more community, I think kindy's more community.

INTERVIEWER: So you like the fact that there's community involvement?

Urban parent 2: Definitely yeah. Well 'because, you know I moved up from [name of place] and like you get to meet everybody, aye.

This connecting with others and building links in the community was continually raised by the parents:

Urban Parent: In a kindergarten situation you meet others parents and all of a sudden you start, you know, having play dates and stuff after kindy and you help out with each other's children if you can't pick them up. 
Urban Parent: At daycare I never met the parents 'cause they're all just in a hurry to get and get out and get back to work or go home.

For parents who had relocated to areas and had not known people the link through the kindergarten had proven to be a key for their families, both for general friendships but also for those times when family and family members are often depended on for support, such in times of illness or birth of a new baby. For example:

\begin{abstract}
Urban Parent: We didn't know - we came here ... but I mean it's like we didn't even know anyone here really and - and we've met so many friendly people, like all our friends now are from the kindy so. When the baby was born 'cause I was - it really hit home because so many people came by and, you know, like dropped off, you know, a meal or whatever and the baby was in hospital for a few days and just to support us during that time was - it was amazing ... it was great.
\end{abstract}

Parents regularly used terms such as 'networking', 'linking' and 'getting to know people' when talking about themselves and their kindergarten, and 'making friends' when talking about their children:

Urban Parent: I think there's a re- like there's
the sense of community not just - just being part
of a family, which I thinks important, but the
fact that you're networking, you might just walk
home with another group of kids, you know, the
same direction or ...you might meet up at the
park and the kids - kids just feel like they - they
know other people. And I mean my childcare,
because I don't have family here, are usually
my kindy friends, you know, whereas I didn't
even know any of the parents at the childcare
centre.

The parents discussed the way in which kindergarten offered parents a way of joining the community, and a couple of parents mentioned the friendships they were able to form with other parents at kindergarten. Parents mentioned the difficulty, even impossibility, of forming social relationships at other EC centres because parents did not stick around and talk to each other:

Urban Parent: The big difference I noticed between kindy and childcare centre was you never got to meet the parents of people at the childcare centre, you drop them off at whatever time you're on - on your way to work, or whatever, it's usually, you know, you've got five seconds to drop and run and if it doesn't fit in with the same schedule as other people you never meet the parents, you never feel part of a - a group, whereas the friendships, you know, we make as a family have been really, really good at kindy, so yeah.

These features of the kindergarten cannot be underestimated in its important role both for individual families but for the supporting and building of communities, and local social capital (as has been found in other studies [24-31].

\section{Changes to Sessions and Involvement of Parents in Deci- sion-Making}

When the parents were asked about a possible move to longer hours at kindergarten, perhaps in relation to school hours or longer, most responded that they thought that this would not be good and that the distinctive nature of kindergarten would be lost:

\begin{abstract}
Urban Parent: I think they should just leave kindergartens as kindergartens. Early childhoods as early childhood centres and give parents choices where they want to go instead of just making them all. They're almost like a business, you know, service money, money, you know...I'm just saying that - if - I'm thinking that, you know, like for me, I mean I had to go back to work, and I'm paying an institution to look after my child and it worries me that I feel more happier sending them to kindy than an institution where I'm paying lots of money.
\end{abstract}

Several parents argued that kindergarten would run the risk of being 'like childcare' and that parents would simply drop off their children and go, removing the important aspect of parental involvement. Most parents identified that working parents had a myriad of choices for EC options, and saw that the current kindergarten provision was the choice for parents such as themselves - a choice and experience they did not want to lose:

Urban Parent: I feel quite strongly about it because I think that kindergarten is a communitybase that's totally different from daycare and that for working parents there are just a myriad of options. There's a hundred and one different options, that as a parent who chooses to stay at home ... don't have those options available, I don't have that money just to just make that decision to book him into a daycare three times a week. I like the fact that it's sessional because I still get to spend time with my children before they go to school for six hours a day and I can take them to preschool gym and I can take them to preschool swimming lessons and I can go along to kindy and become involved there too and I know a lot of working parents who work part-time and make it work with kindergarten and I think it's a really valuable.

A few parents did think that longer hours would suit their working life, and several argued for changes to sessional times to suit children's activity phases throughout the day. The school holiday/term breaks were raised as an issue by several parents who found both the inconvenience of having to find other care over these times, and for re-settling their child back into the programme as a challenge:

Urban Parent: I have to say that one of the other advantages of early childhood centres is they don't have school holidays. So you have that - that care throughout the year rather than, you know, these periods, you know, which which is fine but if you do have other things that you're doing I mean that - that was some- 
thing I did like about [name of a full-day centre].

What was distinctive, in the parents who participated in these interviews, was that the majority of them appreciated having a chance to spend time "with their child", while appreciative also of the break that kindergarten gave them from their child. The following example highlights this:

Urban Parent: It is - it is slightly nostalgic [talking about kindergartens the way they have always been] but I also think that that system meets the needs - well it meets...my needs, I don't need [child] to be in care but I want him to be in a learning environment like that... where he can go, not for the whole day, but he can go for a couple of hours with the other kids that are there for a couple of hours and go for it for two hours and then come home.... You know I - yeah, it meets - it meets our needs. And I guess that's why people - for some people it doesn't meet their needs and I guess that's what the issue - the issue that Kindergarten's grappling with at the moment.

One parent expressed the suggestion that maybe as a society we were expecting kindergartens to fulfill to many functions for society and had lost sight of what the goals and objectives for the kindergarten actually were:

Urban Parent: Well, I think that we expect too much from our kindergartens to be honest 'cause I think when I send my - my son to kindergarten, what they do with him is just fantastic and there's only so much they can do with them, given the funding which isn't their fault, you know, given the ratios. At the end of the day as a parent I think you take your own responsibility for your children's education and what they're not getting at kindergarten you should be doing with them at home.... I'm quite passionate about that really. If your child isn't, you know, isn't kind of competent to doing something you should really be spending a lot of time with your own children 'cause they are our children they're not the teacher's children, they're our children.

In relation to the topic of extended hours, a couple of parents offered a broader critique in which they commented explicitly on government pressures to get mothers back into the paid workforce and on the pressure to maintain kindergarten enrolments. One focus group wondered where the push towards longer hours was coming from:

Urban Parent: And it'd be interesting to actually see where the push has been coming from to actually extend kindergartens. Whether it's the actual parent's request, you know, parents actually voicing it or is it a political money-making business something, I don't know. There'd be a lot of parents ... I've talked to and, you know, they love kindergartens and they don't want extended hours and they have the option of an early childhood centre, so why touch kindergarten, so I don't know. $2^{\text {nd }}$ Urban Parent: Maybe that's the issue - who is the kindergarten for, is it for the kids or is it for the working parents? Is that where the push is coming? If it's for the working parents then yeah this whole structure's going to change isn't it?

And others stated with real emotion:

Rural Parent: Getting women back into working early at the - at the expense of children. My personal opinion is that until a kid's five or six they really, really need their mum and dad and not be put into childcare for forty hours a week and I know that some people choose to but my personal opinion is that they need - they need their time with their parents.

Urban Parent: And there's always going to be people - even though the workforce, you know, people are going back to work more or whatever, I still think there's always going to be people like us that - that you know make that decision to go to one income for the sake of their children and want - and want a sessional kindergarten. There's always - I mean that's not going to ever disappear, who's going to cater for those people?

The move to change to a more 'childcare' model within the kindergarten was seen to undercut this current strength:

Urban Parent: Well, that's what I'm saying about the focus on the parent rather than focus on the child.... So trying to satisfy the parent that's paying the money, you're not focusing on the child's...

$2^{\text {nd }}$ Urban Parent: I got - I got told that by the daycare...

$1^{\text {st }}$ Urban Parent: Child gets compromised.

$2^{\text {nd }}$ Urban Parent: ... saying that: well, you know, it's different for us because obviously the parents are paying our wages so we have to cater for their needs.

$I^{\text {st }}$ Urban Parent: I understand that but it's really sad when you get, I don't know, fifteen bits of artwork and you can't tell who actually did it because of all the paint and can you tell me which one is [child's name] and they can't even pick out which one's his. Yes it looks pretty on the wall but I mean that's...

$2^{\text {nd }}$ Urban Parent: What have they learnt?

$1^{\text {st }}$ Urban parent: ...you know it's giving up 'child comes first' and I just think that's awful let's keep it that away.

Maintaining and keeping choices was seen as important by almost all of the parents. They acknowledged that kindergarten was a 'choice' that they had made, often at personal and family cost, and so other families had similar 'choices' to choose a full-day service or kindergarten:

Rural Parent 1: Because at the moment there's such a nice diversity of choice, something that would suit everybody and that would be a shame to lose kindy as - as a choice. It has been such a 
New Zealand thing, I don't know if other countries have it that way, but such a thing about New Zealand and I think in our part like it would be a shame to lose it as a choice for us.

Rural Parent 2: Because we're - we're with people that aren't working, they're at home mums, like where would they, you know, where would their children go, nowhere till school? You know like if there was no kindies.

The passion that the parents' shared their feelings and ideas on this topic has not been easy to express in the findings here, but was strongly evident in the interviews. The parents demonstrated feelings of pride in their kindergartens, protection for the services they currently used, and concerns that their unique positions (as part-time EC users) were being undermined by policies and politics that they had little to no say in.

\section{Kindergarten is what you do - The Captured Clients}

Rural Parent: I think New Zealanders just think its part of - just a part of the... it's a given. It is a given. Yeah and yeah so people don't even think about it, they just know that's probably where they're going to go.

A large number of the parents had been kindergarten children themselves and this had been a factor in their perception of the 'appropriateness' of sending their own child/ren to kindergarten:

Urban Parent: That's why kindergartens are great because parents can remember that from when they were kids can't they. You can remember that.

Rural Parent: I mean some people choose kindy because it's what they went to. They went to kindy as kids, so my kids should go to kindy. You know, it's just yeah [a] tradition thing.

A couple of parents who had not been to kindergarten themselves suggested that they had missed out (or their mother had missed out) in not having had these experiences themselves:

Rural Parent: I wanted my kids to go to kindy because I didn't. I wasn't a Playcentre baby, I wasn't a kindy kid, I wasn't a daycare kid, I was a 'stay with mum till you're five and you go to school'. And I - I don't remember a lot of it but I thought: I'm never going to do that with my kids, I want them to have [early childhood education].

Tradition has played a key part in the decisions the parents made to choose kindergarten as an EC provider for their child/ren but it was one of the factors and interplayed with the other factors already discussed. It is timely however, to remember this as factor in people's thinking, as it may not be a factor that continues as fewer families choose kindergarten in the future, and it may also be an important 'reminding factor' for communities.

\section{CONCLUSION}

Rural Parent: I think there's something very special about kindergarten. That it's very hard to look at the questions and put your finger on and sum up what it is but I think it's going to be really important that we get that out to the community - which it is a very special place for the children to be.

Overall, these finding are consistent with other research that has looked at parental choice and access to early childhood services in New Zealand and internationally.

Taken together these findings can be seen to be integral in the perception that kindergarten is the 'preparation for school' both in terms of educational objectives but also in the social links of building relationships and friendships between sameage peers and between parents who will move to school together. The sense that kindergarten is part of New Zealand 'tradition' and it is just expected that your child will go, appears to have been an important 'recruitment' for enrolment for children in the past and for the parents in this study. These parents emphasized the traditional nature of attending kindergarten to an extent that has not appeared in other studies, but this will have been because they were specifically asked their opinion on this matter. If this is to continue the findings from this small study indicate some key issues that could be addressed for the future, where kindergartens no longer have the dominant position for the provision of education for three and four year olds in New Zealand.

Currently, difference in early childhood education is still being equated with differing standards of quality despite the standardisation of training, regulations and curriculum, which has shaped the EC scene in New Zealand over the last 20 years [32]. The parents' responses here demonstrated that the traditional dichotomy between childcare and kindergarten is still alive and well in the minds of the parents and experience with both of these sectors seems to have confirmed these perceptions rather than broken them down: child care is for working parents who need somewhere to 'drop their child and go' and kindergarten is for children and education and community connectness. These same views have also been demonstrated in other research undertaken by the author of this paper in talking with parents' use of both kindergarten and other early childhood services $[11,30]$. There is reason for all of those of us who work in EC to be concerned at this. This may become a particularly difficult issue for kindergarten associations who are diversifying into also providing childcare services.

Arguably, many of the things identified, as those that kindergartens do particularly well are things that are good EC practice at any centre. So what is it about kindergarten that these are more readily identified or contrasted positively in comparison to other centres? Is it the expectation that they will? Or are the current structures of kindergarten ones that are more familiar to ex-kindergarten children themselves, in comparison to other centres. Again, this may well change over time as more parents have had childcare experiences, rather than kindergarten experiences.

However, I suggest that there are lessons to be learned and insights to be gained from these parents' perspectives. The aspects of kindergarten that have been identified as important to parents will be a deciding factor for whether these same families, and those like them, will continue to use kindergarten or make different decisions and choices in the future. In making decisions with regards to the future of the kindergarten 
services I conclude with a quote from American Elizabeth Graue:

This decision making process should take into account research knowledge about scheduling and should be premised on equity. ... The key is responding mindfully, in a way that builds on shared ideas about the goals of early schooling, the growing knowledge base of developmental practice, and the changing needs of children, their families and teachers. It would be a mistake to merely react out of allegiance to the past or against the demands of others [Emphasis added]. We need to reflect on what we want kindergarten to be and then plan accordingly. The world of kindergarten is not black and white, play or work, drill or social interaction [2].

\section{ACKNOWLEDGEMENTS}

This research was funded by the University of Otago's Research Grant (2006) and supported by the University of Otago's Divisional Research Grant (2007). I wish also to acknowledge the support of the twelve associations who enabled the research reported here to be carried out, with both philosophical and practical support, and who have been patient in awaiting the results. I thank you once more! I wish also to acknowledge the following research assistants for their help in the wider project: Cushla Scrivens, Jessica Tuhega, Clare Harper-Lee, Eileen Kennedy, Matthew Robertson, and Cameron Duder.

\section{REFERENCES}

[1] Davison C. The sinking of the early childhood education flagship? government's plan to privatise kindergartens: the bulk funding story. Wellington: Institute for Early Childhood Studies 1997.

[2] Graue ME. What's going on in the children's garden? Kindergarten today. Young Children 2001; 56(2): 67-73.

[3] Dunedin Kindergarten Association. Dunedin Kindergarten Association Centennial Booklet, 1889-1989. Dunedin: Dunedin Kindergarten Association, 1989.

[4] Education Review Office. What counts as quality in kindergartens. Education Evaluation Report: Education Review Office; Summer 1997. Report No. 1.

[5] Levitt PS. Public concern for young children: a socio-historical study of reform, Dunedin, 1879-1889 [PhD]: University of Otago 1979.

[6] May H. The 'playground' of early childhood policy. Social and political change versus social and political order. Paper presented to the Policy, practice and politics: early childhood millennium conference, 2000, Wellington: NZEI Te Riu Roa 2000; pp. 51-60.

[7] Middleton S, May H. Teachers talk teaching 1915-1995. Palmerston North: Dunmore Press, 1997

[8] Ministry of Education. Te Whariki: early childhood curriculum. He Whaariki Matauranga mo nga Mokopuna o Aotearoa. Wellington: Learning Media 1996.

[9] Ministry of Education. ECE Time Series. 2006. Available: URL:www.minedu.govt.nz; 2007.

[10] Wilkins A. Half empty or half full? Florida's voluntary prekindergarten standards. Arrest Insights Educ 2005; 2(1): 1-5.
[11] Duncan J, Dalli C, Becker R, et al. Under three-year-olds in kindergartens: Children's experiences and teachers' practices. Wellington: Teach Learn Res Initiative 2006.

[12] Duncan J, Dalli C, Lawrence J. The changing face of kindergarten: A national picture of two year-olds within kindergartens. New Zealand: Ann Rev Educ 2007; 16(2006): 119-40

[13] Boardman M. Half-days or full days of kindergarten? How and why parents decide. Aust J Early Child 2005; 30(1): 36-43.

[14] Duncan J. Talking personally: kindergarten teachers talk education reforms, 1984-1996. Paper presented at the Pacific Early Childhood Research Assocation Annual Conference 2001; Christchurch, New Zealand 2001.

[15] Barraclough SJ, Smith AB. Do parents choose and value quality child care in New Zealand? Int J Early Years Educ 1996; 4(1): 5-26.

[16] Cryer D, Burchinal M. Parents as child care consumers. Early Child Res Q 1997; 12: 35-58.

[17] Keiningham TL, Aksoy L, Andreassen TW, Estrin D. Does parent satisfaction with a childcare provider matter for loyalty. J Consum Mark 2006; 23(7): 470-79.

[18] Robertson J, Gunn TR, Lanumata T, Pryor J. Parental decision making in relation to the use of early childhood education services. Wellington: Ministry of Education 2007.

[19] Smith AB, Grima G, Gaffney M, Powell K, Masse L, Barnett S. Strategic research initiative literature review: early childhood education. Literature review for the Ministry of Education. Wellington: Ministry of Education 2000.

[20] Mitchell L, Brooking K. First NZCER national survey of early childhood education services, 2003-2004. Wellington: Ministry of Education 2007.

[21] Wylie C, Thompson J, Kerslake Hendricks A. Competent children at 5. Families and Early Education. Wellington: New Zealand Council for Educational Research 1996.

[22] Department of Labour, National Advisory Council on the Employment of Women. Childcare, families and work: The New Zealan Childcare Survey 1998. A survey of early childhood education and care arrangements for children. Wellington: Department of Labour 1999

[23] Smith AB. Early childhood theory, research and policy in AotearoaNew Zealand: their development and linkages. Childrenz Issues 2006; 10(1): 23-29.

[24] Duncan J. Collaborations between New Zealand early childhood centres and community resources. Childrenz Issues 2006; 10(2): 1419.

[25] Duncan J, Bowden C, Smith AB. Early childhood centres and family resilience. Wellington: Ministry of Social Development 2004

[26] Duncan J, Bowden C, Smith AB. A gossip or a good yak? Reconceptualising parent support in early childhood centre based programmes. Int J Early Years Educ 2006; 14(1): 1-13.

[27] Duncan J, Bowden C, Smith AB. Early childhood centres and family resilience: Ministry of Social Development 2005.

[28] Duncan J, Bowden C, Smith AB. Aotearoa New Zealand early childhood centres and family resilience: reconceptualisng relationships. Int J Equity Innov Early Child 2006; 4(2): 79-90.

[29] Duncan J, Bowden C, Smith AB. A gossip or a good yack? Reconceptualizing parent support in New Zealand early childhood centre based programmes. Int J Early Years Educ 2006; 14(1): 1-13.

[30] Duncan J, Bowden C, Smith AB. Early childhood centres and family resilience. Wellington: Ministry of Social Development 2006

[31] Powell K, Cullen J, Adams P, Duncan J, Marshall K. The effects of adult playcentre participation on the creation of social capital in local communities. Wellington: New Zealand Playcentre Federation 2005.

[32] Duncan J. Connections between early childhood centres and primary school in New Zealand. Ann Res Early Child (Japan) 2006; 28: $5-13$ 